\title{
Transmutation of metal at low energy in a confined plasma in water
}

\author{
D. Cirillo - V. Iorio \\ domenico.cirillo@poste.it_vincenzo.iorio@email.it
}

Laboratorio M. Ruta - 81100 - Caserta, Italy

August 2004

\begin{abstract}
:
Energetic emissions have been observed from an electrolytic cell when tungsten electrodes are used to generate a confined plasma close to the cathode immersed an alkaline solution. In addition, energy generation has been observed, always close to the cathode, along with the appearance of new chemical elements in the experimental apparatus. These elements were not present in the cell before the experiment. This observation is proof of nuclear transmutations occurring within the cell. The results of this research and a theoretical model of the phenomenon were shown for the first time on April 18, 2004 during the second Grottammare (Ap) ONNE meeting in Italy.
\end{abstract}

\section{Introduction}

The new cells described here produce many simultaneous interactions of a chemical and physical nature. Analysis of these events requires a multidisciplinary approach, and opens a complex and not yet completely understood nuclear mechanism. Due to this complexity, the mathematical model needs more study.

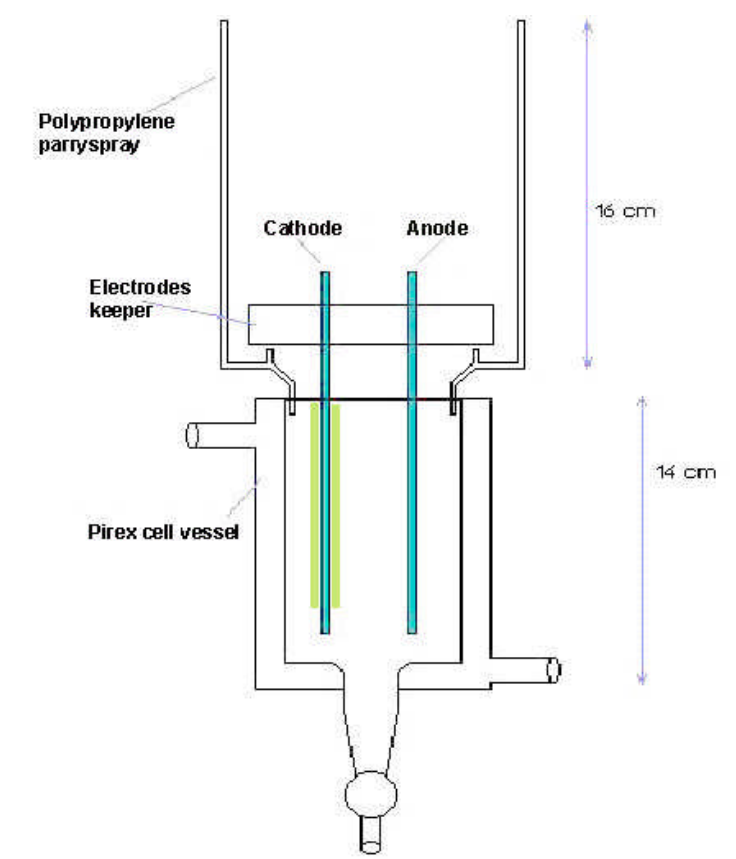

Fig. 1. Configuration of the cell and position of the electrodes

\section{Cell configuration}

The cell, shown in Fig. 1, is made from a $350 \mathrm{ml}$ Pyrex container surrounded by a jacket and having an open top. The jacket is evacuated using a vacuum pump in order to reduce thermal loss. On the top side of the cell is located a cylindrical shield made of polypropylene with a diameter of $13 \mathrm{~cm}$. and a height of about $16 \mathrm{~cm}$. A lid made of Plexiglass closes the cell top. The electrodes, a thermocouple and a mercury thermometer pass through holes in the lid. 
The electrodes are cylindrical rods with a diameter of $2.45 \mathrm{~mm}$, and a length of $17.5 \mathrm{~cm}$. Both are made of pure tungsten, with a combined volume of $3.8 \mathrm{~cm}^{3}$. The cathode is partially covered with a ceramic sleeve, which allows us to control the dimensions of the exposed cathode surface submerged in the reacting solution. Transducers are placed close to the cell and connected to various measuring instruments, consisting of a pyrometer and light-meter to measure the light variations occurring inside the cell, and a Geiger counter, to measure the radiant emission caused by nuclear events. We find that RF interference can cause incorrect readings. This will be discussed later. The cell is powered by a direct current power supply able to output a variable voltage from 0 to 340 volt and a maximum current of $8 \mathrm{Amp}$. The electrolytic solution is potassium carbonate $\left(\mathrm{K}_{2} \mathrm{CO}_{3}\right), 0.2 \mathrm{M}$ concentrated in $200 \mathrm{ml}$ of ultra pure water (double-distilled), which has a $\mathrm{pH}$ greater than 10. This solution is standardized with a volume of $200+/-0.5 \mathrm{ml}$ at $20^{\circ} \mathrm{C}$. The solution is heated to $70^{\circ} \mathrm{C}$ so that an electrical conductivity of $12000 \mu \mathrm{S}$ is obtained. This condition favors formation of a plasma and facilitates the nuclear events, as we will explain below. From a thermodynamic point of view, the cell is a non-adiabatic calorimeter, because it loses heat from the top, and constant pressure, because it is always in contact with the ambient atmosphere. Even a strong vapor emission is quickly dispersed without over-pressure generation.

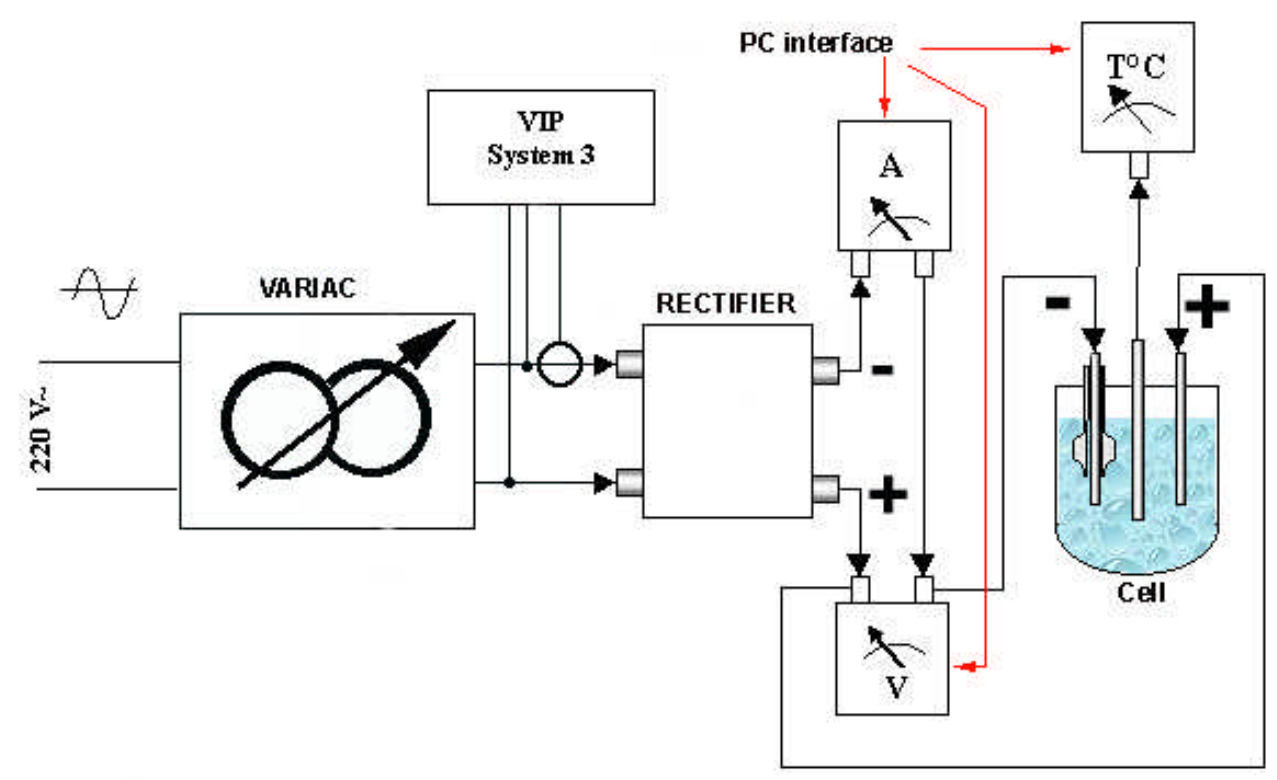

Fig. 2. General layout of the cell system. 


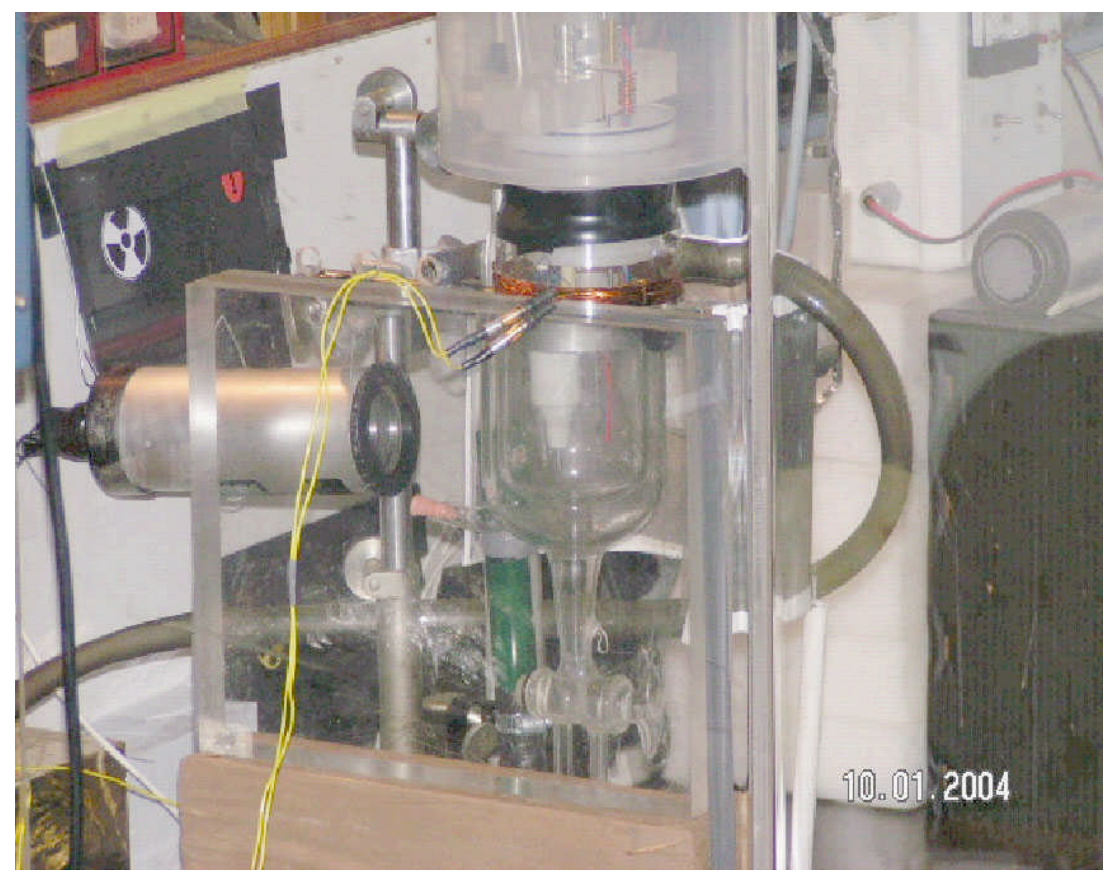

Fig. 3. Electrochemical Plasma Cell

\section{Electrochemical Plasma Cell working conditions.}

Application of the voltage causes $\mathrm{H}+$ to migrate to the cathode (the electrode that is at negative potential) and $\mathrm{OH}$ - to migrate to the anode (the electrode at a positive potential). This ionic flux allows current to pass through the cell and produces hydrogen at the cathode and oxygen at the anode. The oxygen is produced through the ionic $\mathrm{OH}$ - discharge at the anode, and the hydrogen mainly through the direct discharge of the water molecule at the cathode, following the reactions:

Cathode: $2 \mathrm{H}_{2} \mathrm{O}+2 \mathrm{e}^{-}=\mathrm{H}_{2}+2 \mathrm{OH}^{-}$or $2 \mathrm{H}_{3} \mathrm{O}^{+}+2 \mathrm{e}^{-} \rightarrow \mathrm{H}_{2}+2 \mathrm{H}_{2} \mathrm{O}$

Anode : $4 \mathrm{OH}^{-}=2 \mathrm{H}_{2} \mathrm{O}+4 \mathrm{e}-+\mathrm{O}_{2}$

The overall cathode reaction is strongly enhanced by the electrolytic. For example, the potassium ions $(\mathrm{K}+)$ that are dissolved in the solution have a greater oxidation potential than hydrogen. The cathode reaction will last until all the hydrogen disappears from the solution. Simultaneously, the potassium ions will condense around the cathode, without depositing on it, thereby generating a screen with a positive potential that holds itself a few $\mathrm{nm}$ from the electrode. This peculiar configuration is similar to a cathode condenser in which the positive electrode is created by the potassium ions and the negative electrode is the cathode itself. In this situation, the dielectric is the double layer consisting of $\mathrm{H}_{3} \mathrm{O}^{+}$and $\mathrm{H}_{2}$ located between the two electrodes. In spite of this screen of potassium ions, ions of the hydrogen, being much smaller, will continue to discharge on the cathode without difficulty and generate gaseous hydrogen. (Hydrogen ions are so small, they are practically protons, in some ways.) 


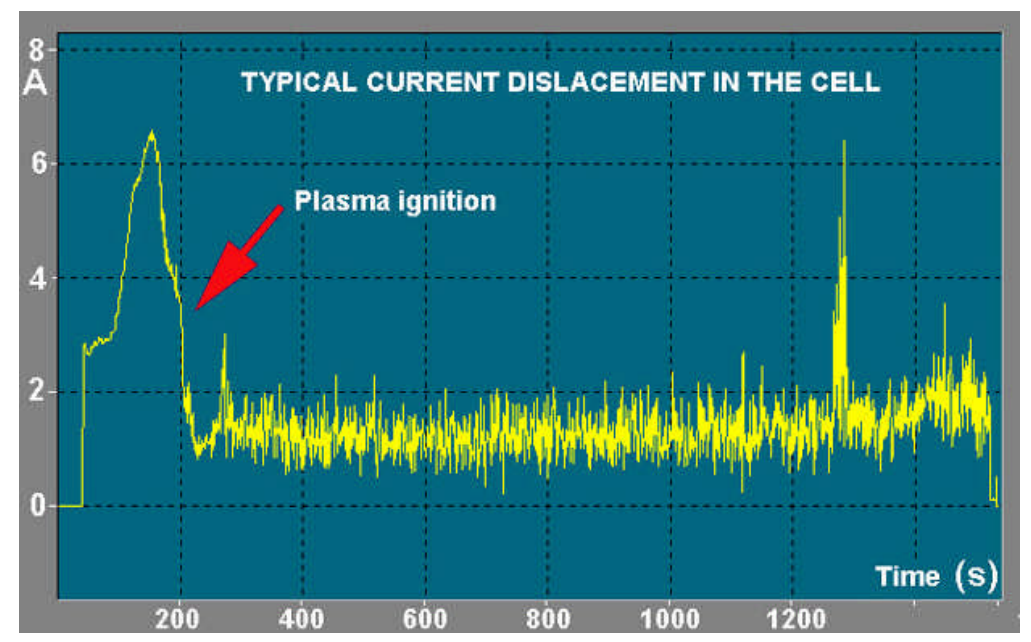

Fig. 4. Current displacement in our cell

Normal electrolysis occurs as long as applied voltage is around $50-80 \mathrm{~V}$. As the voltage is increased on the order of hundreds of volts, the amount of hydrogen generation increases significantly. Eventually, so much hydrogen is being formed that it blocks the electrode. This causes the resistance of the cell to increase according to the equation $R_{(T)}=R_{(T o)} *\left[1+\alpha\left(T-T_{0}\right)\right]$ in which $R_{(T)}$ is the actual electrical resistance, $R_{(T o)}$ is its value at $20^{\circ} \mathrm{C}$, " $\alpha$ " is coefficient typical for tungsten $(0.0045)$, and $\mathrm{T}$ is the temperature at which resistance is measured.

Once the region near the cathode acquires a sufficiently high resistance, the voltage drop between the potassium ion shield and the cathode can cause a plasma to form, thereby forming a gaseous dielectric. The new condition can be represented with the equivalent circuit as shown in Fig. 5, where $\mathrm{Z}_{\mathrm{f}}$ is the Faraday impedance.

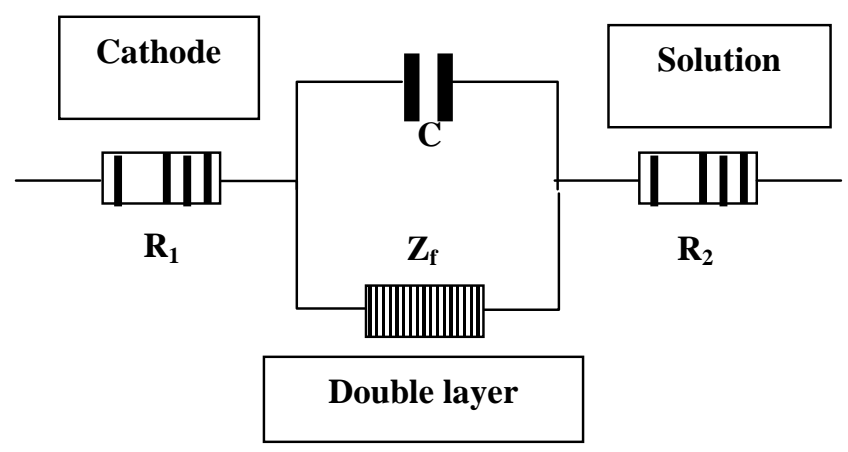

Fig. 5 Electronic representation of the double layer.

This plasma is unstable and will tend to be strongest where the voltage is greatest (see Fig. 6). The high local voltage is able to excite hydrogen and potassium ions to energies that result in optical emissions. In addition, the tungsten rod is heated to a temperature that produces electron and light emission. As a result, strong RF emissions are produced that can interferer with measurements if adequate shielding is not used. 


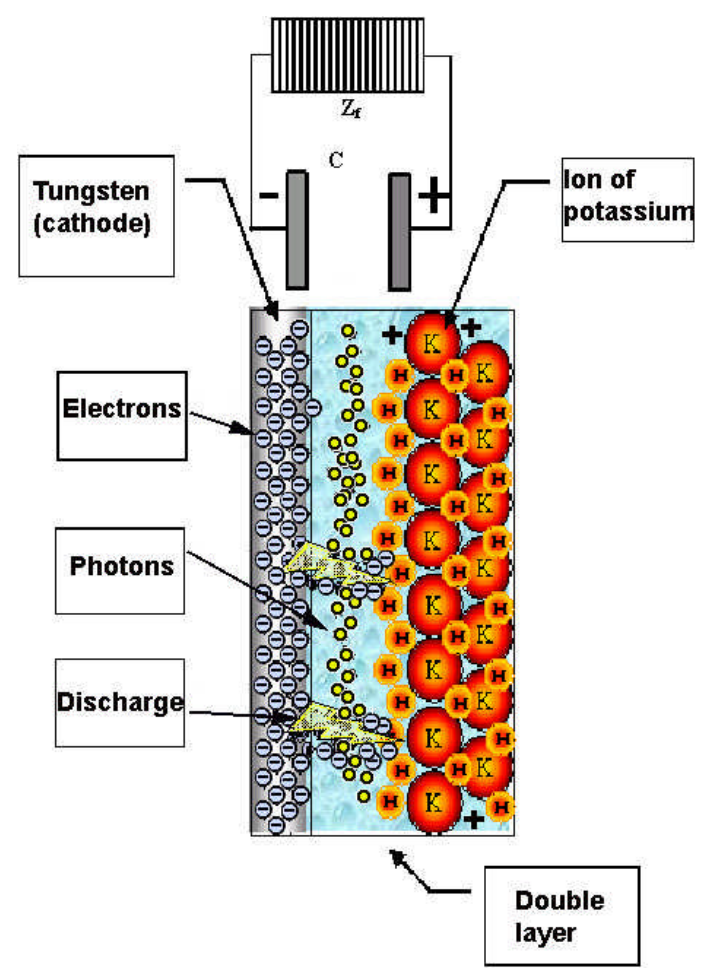

Fig. 6. Describing the Double layer during the ignition phase

All together this phenomenon rises the cathode temperature close to $500^{\circ} \mathrm{C}$., giving birth to an important consequence: the water in the solution, finding itself very close to the cathode, will evaporate instantaneously, generating a sort of vapor-sleeve.

As a result, the electrical conduction mechanism in the cell changes. The region covered by plasma is much less involved in electrical conduction through the cell causing conduction to shift to the upper cooler part of the cathode, called "reaction band", where gaseous hydrogen continues to be produced, but hydrogen formation is reduced. This causes the current to stabilize at about $1-1.5 \mathrm{~A}$, as observed during the ignition phase (see Fig. 4). The limiting current value depends only on the ion concentration. This demonstrates that when the cathode surface is covered with the plasma, electrical conduction is drastically reduced and electrical potential lines are obliged to concentrate at colder areas, as shown in Fig. 7.

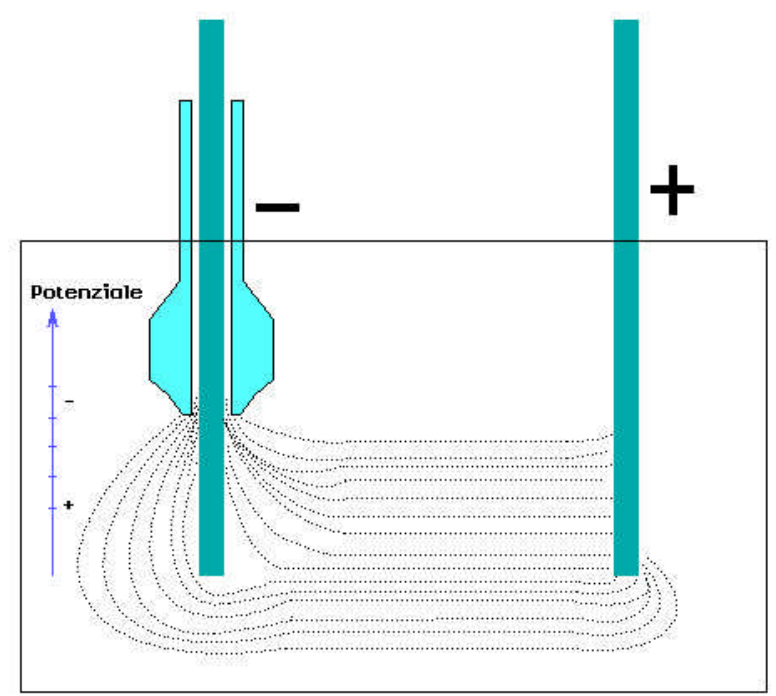

Fig. 7. Flux of the ions in the solution 
Important to the process is the cathode ceramic sleeve, called "reaction chamber", which offers, thanks to its geometry, the correct electrical stability to the plasma. The internal diameter of the reaction chamber is larger than the cathode diameter by few millimeters.

The following X-ray photos picture (Fig. 8, 9) show the tungsten surface after a good test of 4000 seconds. Photo 1 shows very little etching of the surface, while Photo 2 shows areas where tungsten melted, indicating a temperature higher than $3400^{\circ} \mathrm{C}$.

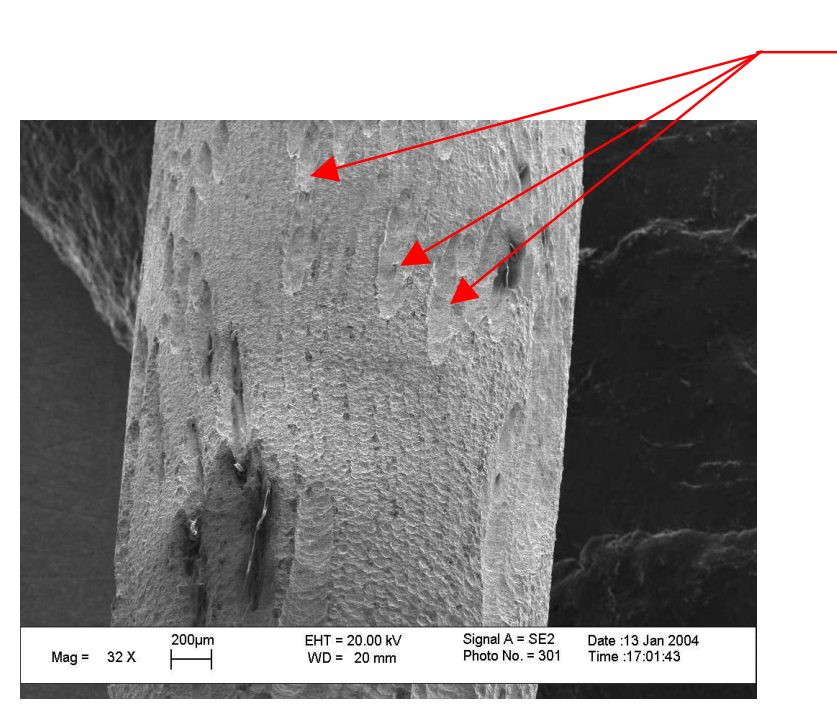

Worm gas erosion

Fig.8. Areas etched by hydrogen gas

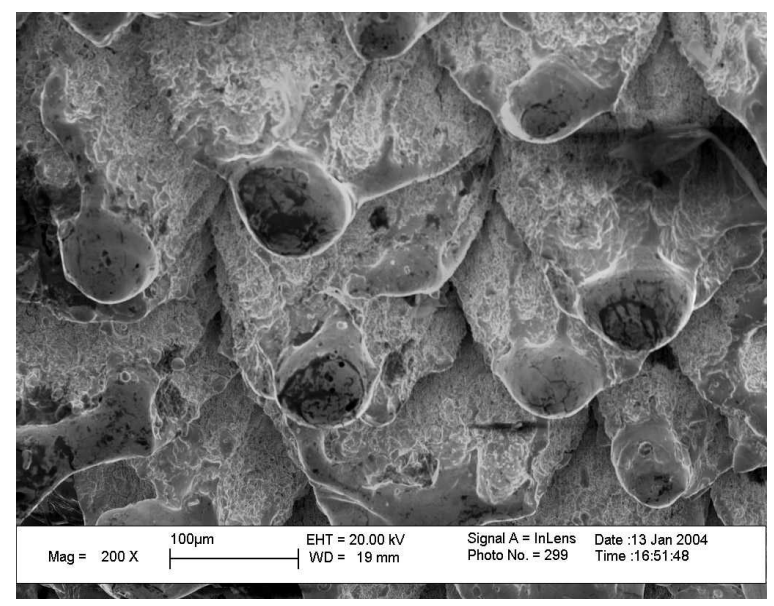

Fig.9. Tungsten fusion area (after 4000 sec.)

Important to creating a model is the realization that temperatures in excess of $1000^{\circ} \mathrm{C}$ are produced, and they sometimes as high as $3400^{\circ} \mathrm{C}$. Such temperatures generate thermionic emission, which must be considered.

We propose that as the temperature increases, electrons in the metal start to oscillate in a coherent way. This oscillation is attracted toward the metal surface by the surrounding positive potassium ions. In addition, at temperatures close to $3400^{\circ} \mathrm{C}$, thermonic emission can generate as much as 500 amperes from the heated part of the cathode. (See Fig. 10). Therefore, a considerable number of electrons are available to the surface region. We believe this condition is important to initiating the observed transmutation reactions.

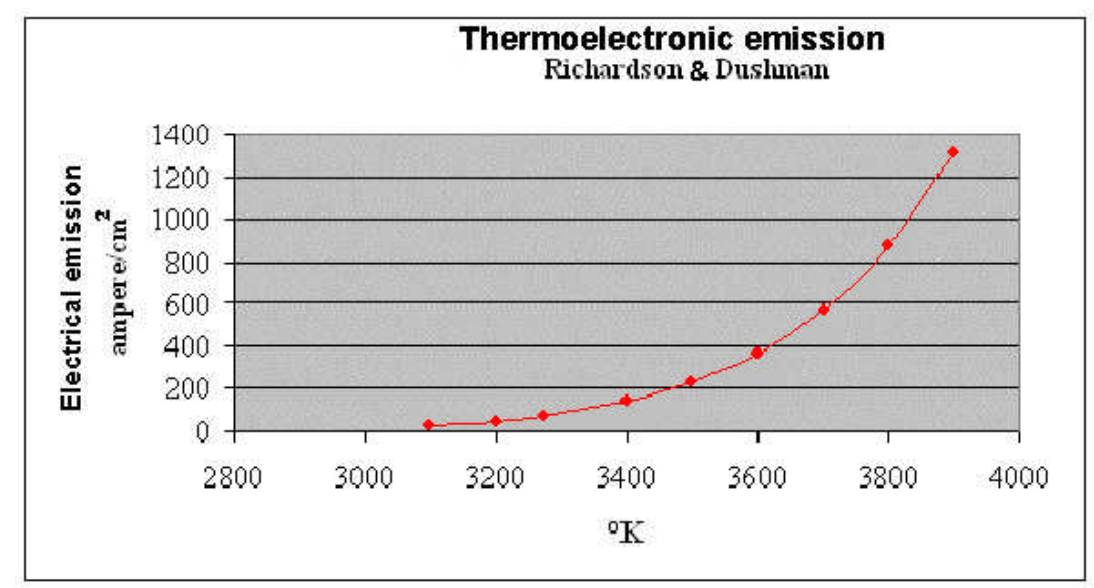

Fig. 10. Tungsten thermoionic emission 


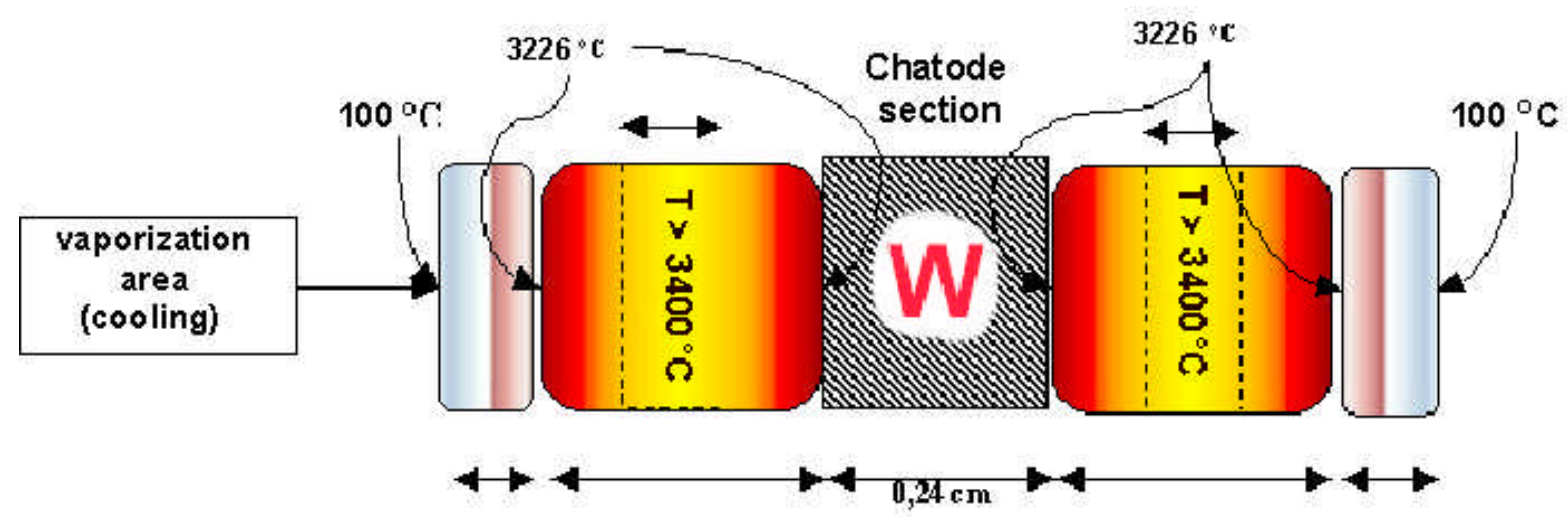

Fig. 11. View of the plasma heat transfer mechanism

\section{Experimental evidence}

Once a stable plasma has been achieved for more than $500 \mathrm{sec}$., we can compare the input energy, electrical power, with the quantity of energy necessary to warm up and evaporate the solution water. Omitted from this calculation is energy associated with chemical reactions; energy related to the heating-up and fusion of the tungsten; energy used in expanding gas and steam leaving the cell; energy lost by thermal and electromagnetic radiation; and loss of heat through the insulation. Even though this extra energy is omitted from the calculation, the cell is found to produce more energy than is being applied. If the energy needed to warm-up the electrolyte to $100^{\circ} \mathrm{C}$ and then produce evaporation is taken into account, values of output/input $=1.2$ to 1.4 are obtained.

Using an SEM (scanning electron microscope), the presence of rhenium, osmium, gold, hafnium, thulium, erbium, and ytterbium are found on the surface of the cathode. These elements were not previously in the apparatus (see Fig. 12, 13, 14). 


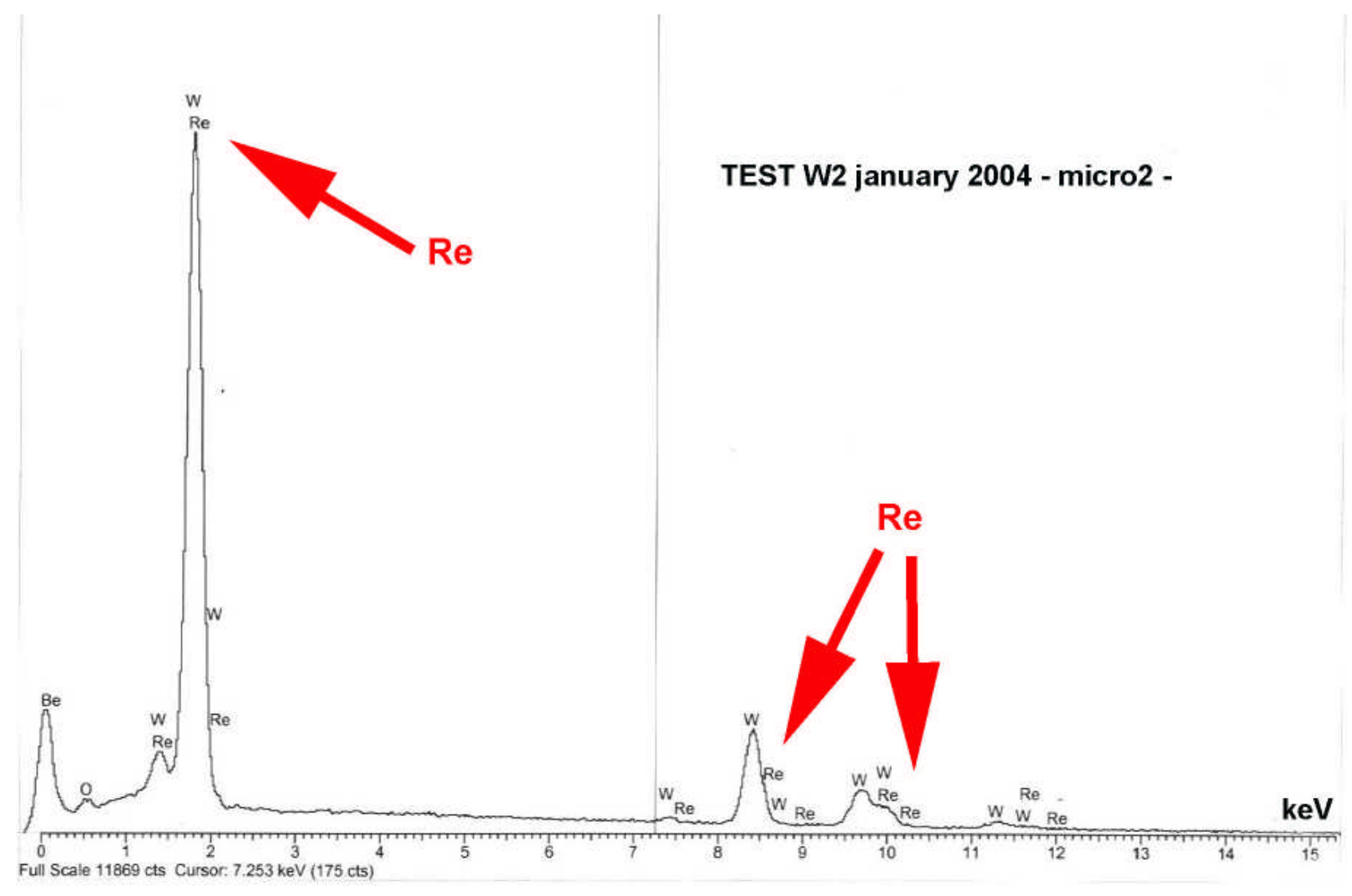

Fig. 12. Analysis executed with an SEM on an area of the cathode surface after 4000 seconds of plasma - January 2004. 


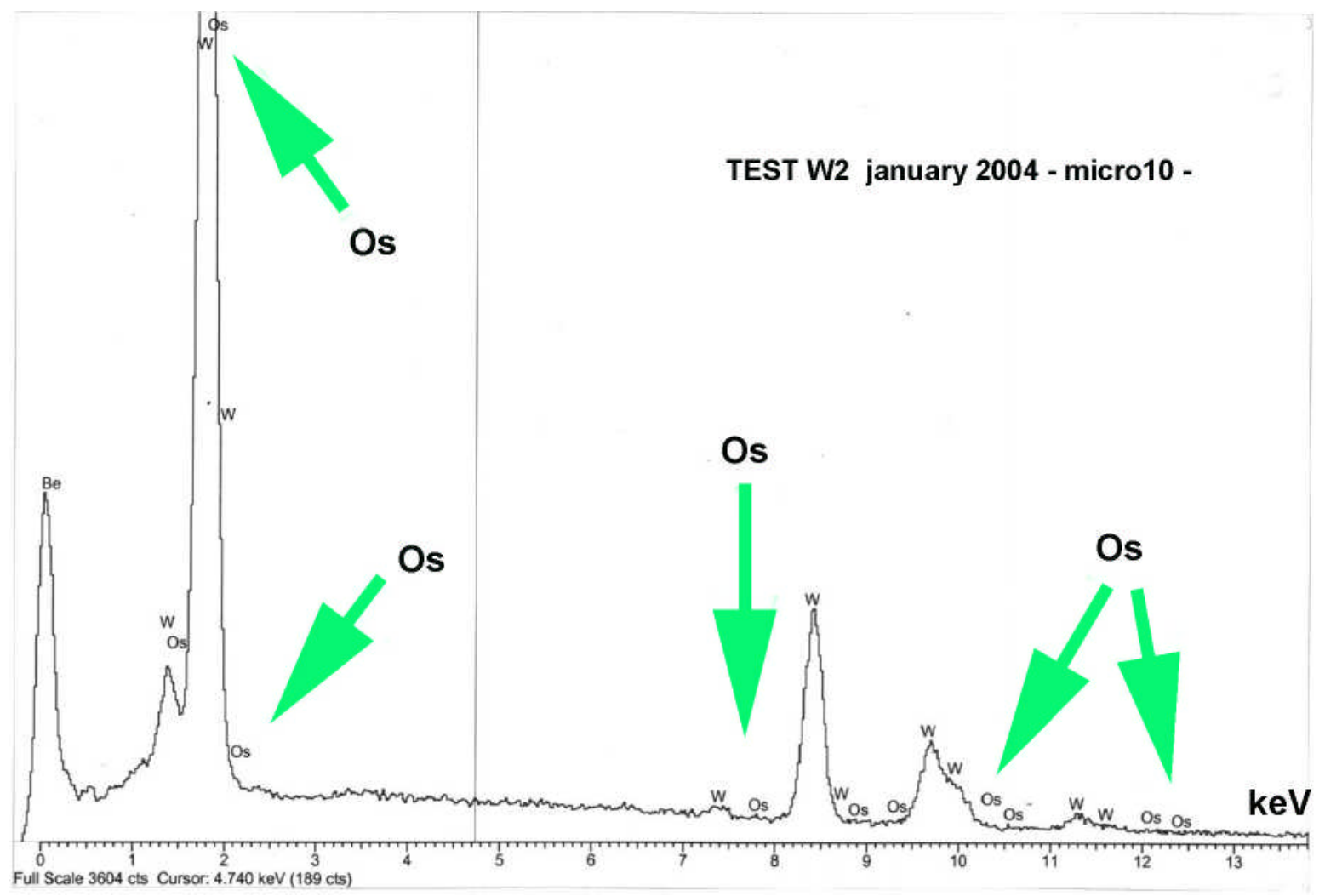

Fig. 13. Analysis executed with an SEM on an area of the cathode surface after $4000 \mathrm{sec}$. of plasma - January 2004.

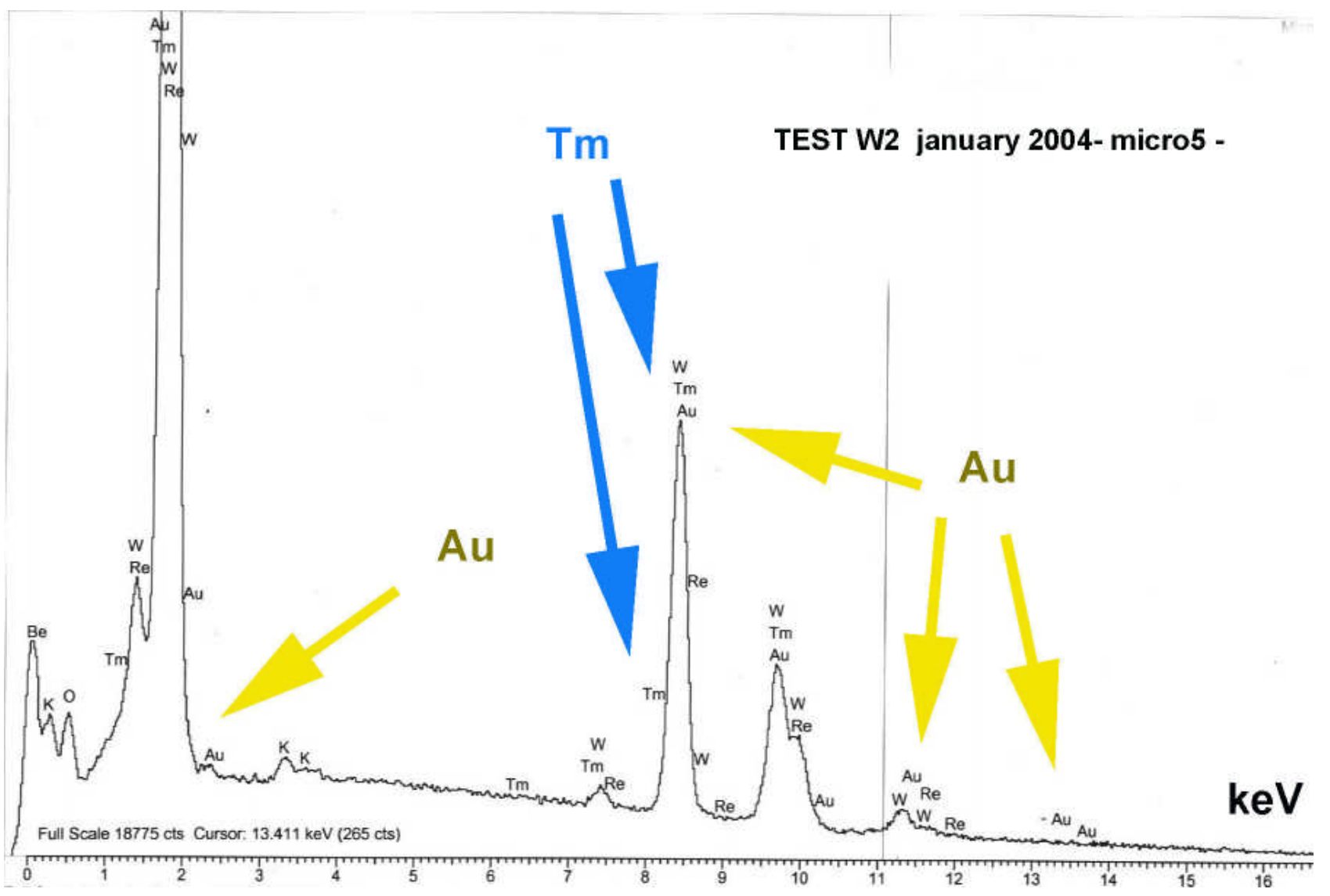

Fig. 14. Analysis executed with an SEM on an area of the cathode surface after $4000 \mathrm{sec}$. of plasma - January 2004. 


\section{Thermodynamic problems and output energy measurement}

The cell is heated mainly by resistive heating and by radiation from the plasma at the cathode. The following formula is used calculate the energy resulting from these processes.

$$
Q_{\text {uscita }}=m_{\mathrm{H}_{2} \mathrm{O}} \cdot\left(T_{2}-T_{1}\right) \cdot c p_{\mathrm{H}_{2} \mathrm{O}}+m_{v} \cdot 539,55
$$

With $\mathbf{m}_{\mathbf{H 2 0}}$ is the solution initial quantity (200cc.), $\mathbf{c p}_{\mathbf{H 2 0}}$ is the specific heat at constant pressure, $\mathbf{m}_{\mathbf{v}}$ is the amount of water lost by vaporization, 539,55) is the heat of valorization given in cal/g, and (T2-T1) is the initial and final temperature of the cell. This method gives a precision of $+/-250$ cal.

Additional factors must be taken into account, including splitting of water into its elemental components. This involves the following reaction, which removes energy from the system.

$$
\mathrm{H}_{2} \mathrm{O}(\mathrm{l}) \rightarrow \mathrm{H}_{2}(\mathrm{~g})+1 / 2 \mathrm{O}_{2}(\mathrm{~g}) \Rightarrow>\quad+68000 \mathrm{cal} / \mathrm{mole}
$$

Energy is used to oxidize tungsten at the anode, as shown by the following reactions.

$$
\begin{array}{ll}
\mathrm{W}+\mathrm{O}_{2} \rightarrow \mathrm{WO}_{2}(\mathrm{c})= & -137180 \mathrm{cal} / \mathrm{mole} \\
\mathrm{W}+3 / 2 \mathrm{O}_{2} \rightarrow \mathrm{WO}_{3}(\mathrm{c})= & -201180 \mathrm{cal} / \mathrm{mole} \\
\mathrm{WO}_{3} \rightarrow 3 \mathrm{O}+\mathrm{W}(\mathrm{l})= & -203140 \mathrm{cal} / \mathrm{mole}
\end{array}
$$

These reactions remove tungsten from the anode and enrich the solution with tungsten oxides. Being exothermic, these reactions add heat to the solution. However, the amount of energy contributed by these reactions is very small.

Strong electromagnetic disturbances in the frequency range between $\mathrm{kHz}$ and hundred of $\mathrm{MHz}$, are generated (see Fig. 15). These signals originate from the plasma in spite of the surrounding liquid.

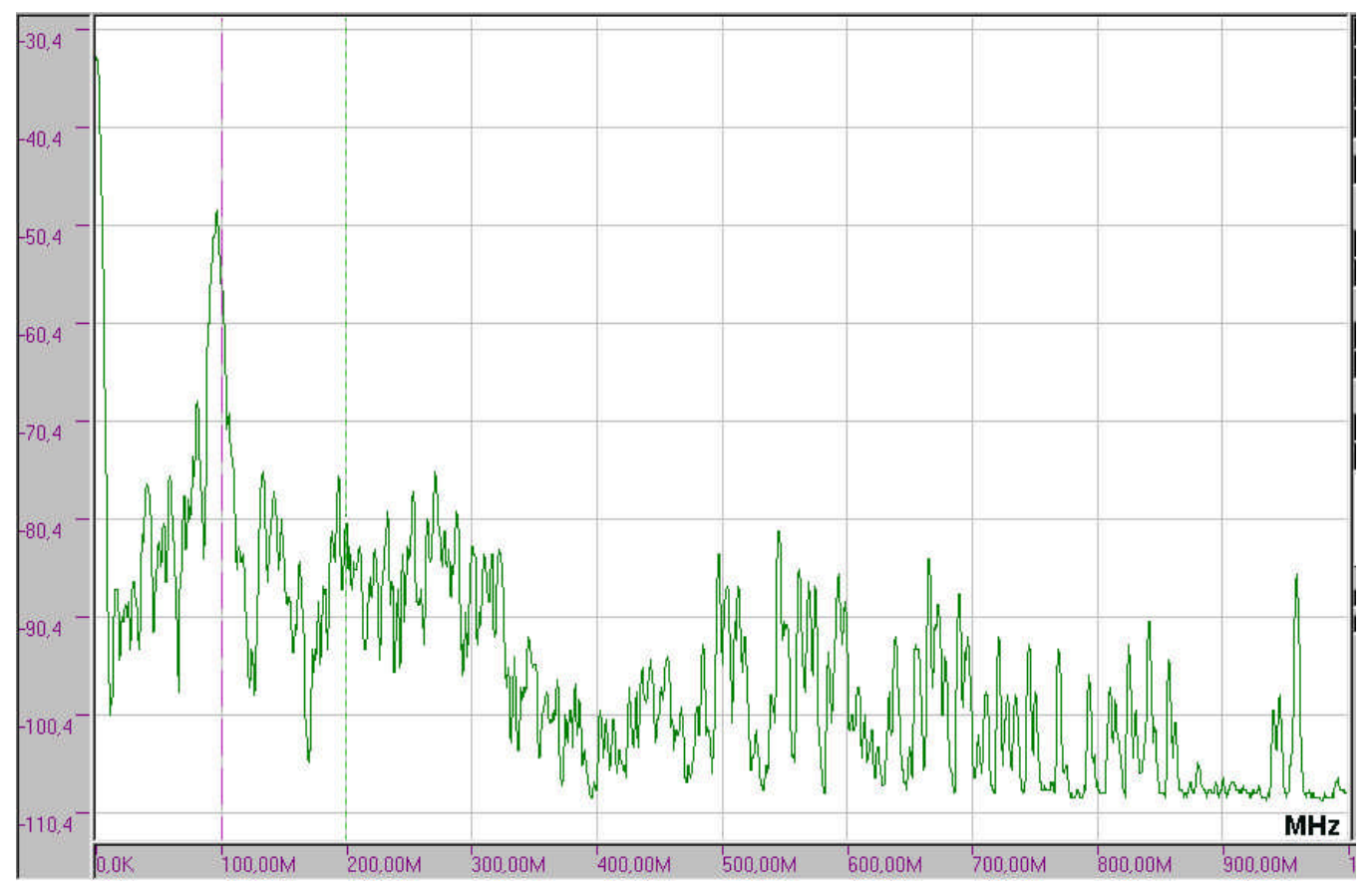

Fig. 15 Electromagnetic spectrum during plasma ignition 
The cell can be analyzed as an electrical circuit shown on fig.17

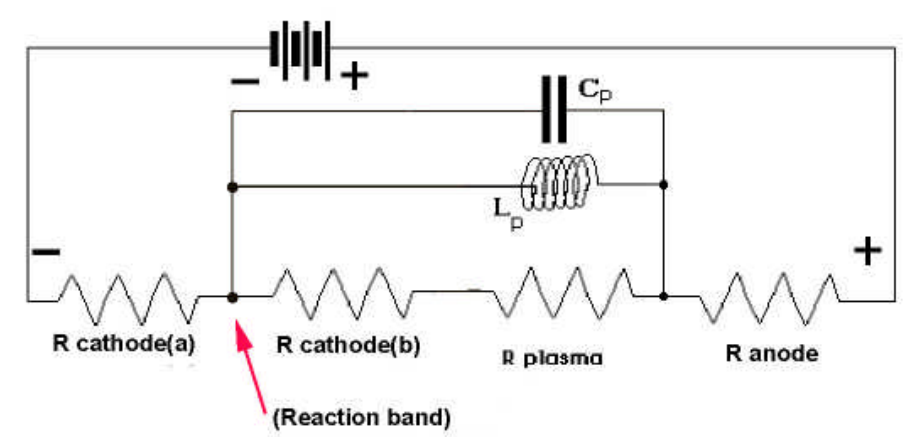

Fig. 17 Equivalent circuit of the cell during plasma phase

$\mathrm{Cp}$ is the tungsten-potassium virtual condenser and $\mathrm{Lp}$ is the plasma inductance. This equivalent circuit allows the oscillations that produce electromagnetic emissions to be analyzed. The equivalent circuit shows a cathode resistance made of two terms ( $\mathrm{Ra}$ and $\mathrm{Rb}$ ), which provide most of the ohmic heating. The highlighted point by the arrow shows the area called 'reaction band', which, as explained above, maintains the cell current once a plasma has formed. A complete analysis of the emitted electromagnetic spectrum should allow the energy generated at $\mathrm{Ra}$ and $\mathrm{Rb}$ to be determined. At the moment these data are still to be determined.

The work of expansion has not been evaluated because the volume of gas has not yet been determined. Therefore, we have not been able to give a value to the ' $\Delta \mathbf{V}$ ', which appears in the equation:

$\mathbf{E}_{\text {(expansion) }}=\mathbf{P} * \Delta \mathrm{V}$

This equation gives the energy associated with expansion of the generated gases when the pressure, $\mathrm{P}$, is fixed.

The thermal losses from the system are approximately $25 \%$ of the input energy (Qinput). This means that when $100 \mathrm{cal}$ is applied to the cell, $75 \mathrm{cal}$. will be transformed into heat to warm the solution and $25 \mathrm{cal}$ will be lost to the environment through the insulation.

\section{Conclusions}

The plasma is able to initiate transmutation reactions. Future studies are underway to understand the mechanism of these reactions. We propose that these reactions are the main source of measured excess energy. 


\section{References}

Ohmori, T. and T. Mizuno. Strong Excess Energy Evolution, New Element Production, and Electromagnetic Wave and/or Neutron Emission in the Light Water Electrolysis with a Tungsten Cathode. in The Seventh International Conference on Cold Fusion. 1998. Vancouver, Canada: ENECO, Inc., Salt Lake City, UT. (ICCF-7)

Scott R. Little, H. E. Puthoff Ph.D., and Marissa E. Little, Search for Excess Heat from a Pt Electrode Discharge in K2CO3-H2O and K2CO3-D2O Electrolytes, September 1998

Ohmori, T. and T. Mizuno, Nuclear transmutation reaction caused by light water electrolysis on tungsten cathode under incandescent conditions. Infinite Energy, 1999. 5(27): p. 34.

D. C. Borghi, D. C. Giori, A. Dall'Olio, CEN, Recife, Brazil, Experimental Evidence for the Emission of Neutrons from Cold Hydrogen Plasma, Unpublished, (1957).

Monti, R.A., Low energy nuclear reactions: Experimental evidence for the alpha extended model of the atom. J. New Energy, 1996. 1(3): p. 131.

Monti, R.A., Nuclear Transmutation Processes of Lead, Silver, Thorium, Uranium. in The Seventh International Conference on Cold Fusion. 1998. Vancouver, Canada: ENECO, Inc., Salt Lake City, UT. 